\title{
An Overview and Comparative Evaluation of Head and Neck Cancer Risk Factors in India and Australia
}

\author{
Satinder Pal Singh ${ }^{1}$, Robert Eisenberg ${ }^{2}$, Gary Hoffman ${ }^{3}$ \\ ${ }^{1}$ Department of Otolaryngology \& Head Neck Surgery, Swift Hospital, Amritsar, India \\ ${ }^{2}$ Department of Otolaryngology-Head and Neck Surgery, John Hunter Hospital, Newcastle, Australia \\ ${ }^{3}$ Department of Oral Maxillo Facial Surgery, John Hunter Hospital, Newcastle, Australia \\ Email: ^satinderpalsingh44@gmail.com,drrobeisenberg@gmail.com, garyhoffman_au@hotmail.com
}

How to cite this paper: Singh, S.P., Eisenberg, R. and Hoffman, G. (2018) An Overview and Comparative Evaluation of Head and Neck Cancer Risk Factors in India and Australia. International Journal of Otolaryngology and Head \& Neck Surgery, 7, 254-267.

https://doi.org/10.4236/ijohns.2018.75027

Received: July 31, 2018

Accepted: August 31, 2018

Published: September 3, 2018

Copyright (๑) 2018 by authors and Scientific Research Publishing Inc. This work is licensed under the Creative Commons Attribution International License (CC BY 4.0).

http://creativecommons.org/licenses/by/4.0/

\begin{abstract}
Aim: An overview and comparative evaluation of head and neck cancer risk factors in India and Australia. Method: In this review we included articles with information on head and neck cancer risk factors and its association based on: smoking tobacco, alcohol, smokeless tobacco, betel nut and areca nut chewing, viral infection like HPV, dental hygiene, diet, family history, socioeconomic status, other heavy metals and systemic conditions. Articles with clinical features, diagnosis, treatment and prognosis were excluded. Results: Head and neck cancer in India has different demographic, risk factors, dietary habits, personal and family history. Oral cancer is more common amongst all head and neck squamous cell cancers in males. This is mainly attributed with consumption of a variety of smokeless tobacco, smoking, alcohol, poverty, illiteracy, cultural, advanced stage at presentation; lack of good treatment infrastructure creates main challenge to India as compared to Australia. Conclusion: The knowledge about risk factors for HNC in public health education for general population supports health promotion and tobacco prevention, which is the main aim of the programs started by the government, as head and neck cancers are potentially preventable.
\end{abstract}

\section{Keywords}

Head and Neck Cancer, Oral Cavity, Oropharynx Smoking and Smokeless Tobacco, Alcohol, HPV, Oral Hygiene, Other Risk Factors

\section{Introduction}

Worldwide, the head and neck cancer (HNC) is the $6^{\text {th }}$ most common cancer; as 
it is considered a lethal disease affecting the upper aero-digestive tract and near about 0.9 million new cases have been diagnosed each year [1] [2]. With 0.47 million cases diagnosed per year in India alone, HNCs are the second most common cancers in the Indian population by National Institute of Cancer Prevention and Research [3]. India contributes up to more than $8 \%$ of the global cancer burden and deaths [4]. Developed countries like Australia present with a maximum $40 \%$ of patients with advanced disease whereas prevalence in developing countries like India is $>60 \%$ of these patients [5].

The incidence of HNC seems to be 12.3 per 100,000 in Australia and 22 per 100,000 population in India, also accounts for about $30 \%$ of all types of Indian cancers [6] [7]. HNC is the most common cancer of males in India and the fifth most common in females [8]. Great difference in mean age of presentation lies in the 5th-6th decade for the Indian population as compared to 7 th-8th decade among the Australian population, also more frequently diagnosed in males than females [9]. In India, 90\% - 95\%, whereas, in Australia more than 90\% of HNC originates from the mucosal lining of the mouth and oropharynx, hypopharynx, larynx, sinonasal tract, and nasopharynx [10].

Most of the HNC cases and deaths are due to the cigarette smoking and alcohol consumption in the global population, which are the major risk factors, along that it has synergistic effect in increasing oral cancer risk whereas smokeless tobacco (SLT), betel nut, and human papilloma virus are etiological agents responsible for it in the Indian population [11] [12]. The various forms in which SLT is used in developing countries include khaini, mava, paan (betel quid), zarda, snuff, mashiri, etc. [13]. The prevalence of HNC in India has different demographic profiles, risk factors, dietary habits, socioeconomic conditions, lifestyles and family history [14]. High incidence of the oral and oropharyngeal cancer is observed among native Australians [15]. Many epidemiological evidences strongly report that many risk factors are not only causal but also associated with an increased risk of HNC occurrence [16].

In India, nearly two-thirds of patients present with advanced stages [17]. Despite advances in treatment methods for HNC, the present treatments improve the quality of life of head and neck cancer patients but the overall survival rate of 5 years has not improved in the past decades [18].

Major aim of this article is comparative evaluation of published data about the prevalence of risk factors for head and neck cancer in India and Australia.

\section{Methods}

We collected data from published literature by carried out a organized search using key words with risk factors, tobacco, alcohol, betel nut chewing, human papilloma virus, environmental factors and other risk factors for HNC from Medline, Pubmed and Google Scholar using a combination of subject headings and keywords.

In this review we included articles with information on head and neck cancer 
risk factors and its association based on; smoking tobacco, alcohol, smokeless tobacco, betel nut and areca nut chewing, viral infection like HPV, dental hygiene, diet, family history, socioeconomic status, other heavy metals and systemic conditions.

We selected the articles carefully after reading abstract and titles to determine whether, they were completely fitted the inclusion criteria for the review. In addition to this, we also studied the references of related articles to find more literature. Articles with clinical features, diagnosis, treatment and prognosis were excluded. Figure 1 shows the flowchart for selection of the articles.

\begin{tabular}{ll}
\hline \multicolumn{1}{c}{ Inclusion Criteria } \\
\hline 1) & Web-based search from Medline, Pubmed and Google Scholar \\
2) & $\begin{array}{l}\text { Carefully review of titles and abstract of selected articles are available } \\
\text { in English and limited to human research }\end{array}$ \\
& $\begin{array}{l}\text { Articles reporting data on association between HNC, HNSCC and risk factors: } \\
\text { (about smoking tobacco, alcohol, smokeless tobacco, betel nut and areca nut chewing, } \\
\text { viral infection like HPV, dental hygiene, diet, family history, socioeconomic status, } \\
\text { other heavy metals and systemic conditions, HNC, HNSCC) completing inclusion criteria }\end{array}$ \\
4) Selected relevant studies for this review article
\end{tabular}

\section{Exclusion Criteria}

1)

Articles with clinical features, diagnosis, treatment, prognosis, and case reports were excluded.
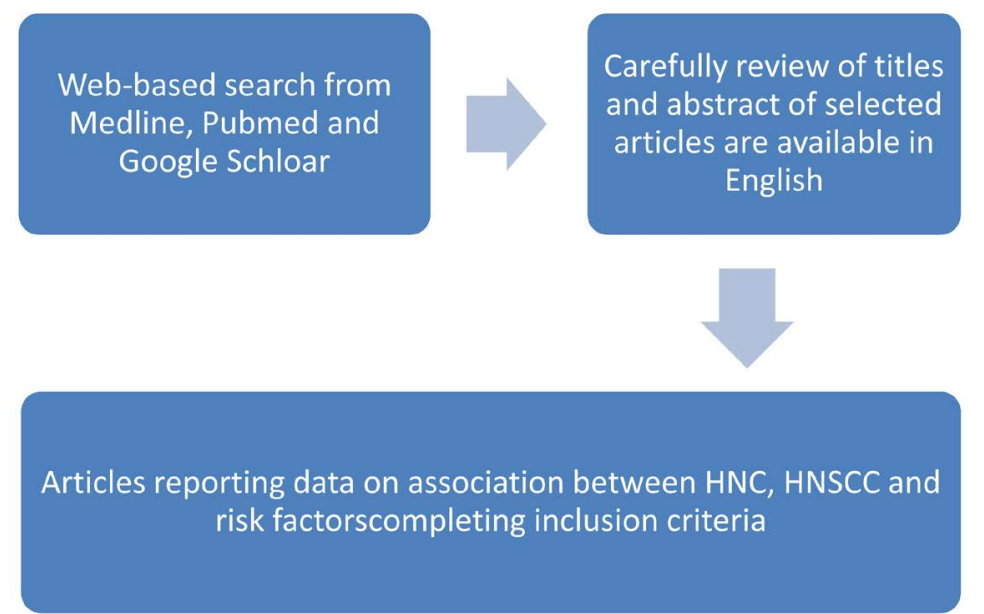
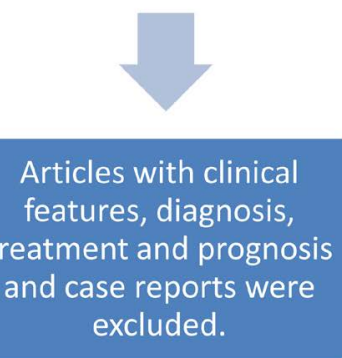

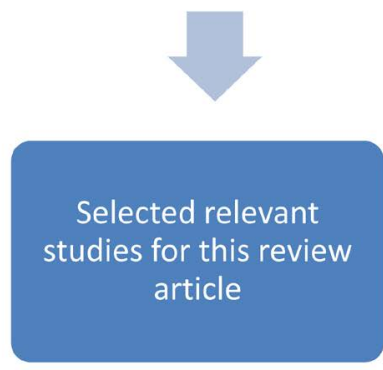

Figure 1. Flowchart for selection of the literature. 


\section{Risk Factors}

\subsection{Tobacco Use}

Tobacco is deadly in any form and its use already has become responsible for more than 6 million deaths worldwide each year. According to the World Health Organization (WHO) estimates, globally, there were 100 million premature deaths due to tobacco in the 20th century, and if the current trends of tobacco use continue, this number is expected to rise to 1 billion in the 21st century [19]. Jha et al. have estimated that around 1 million deaths a year in India will be attributable to smoking by the early 2010s [20]. India's tobacco problem is very complex, with a large use of a variety of smoking forms and an array of SLT products are the most common cause of HNSCC [21].

In India tobacco smoking in the form of cigarettes, bidis, cigars/chutta/cheroot, dhumti (Goa), the water pipes/hookah (north India), reverse chutta smoking (in coastal regions in Andhra Pradesh and Orissa), hookli (Gujarat) and chillum (northeastern parts of India). Estimates indicate $57 \%$ of men and $11 \%$ of women between 15 - 49 years of age use some form of tobacco and an estimate of the Global Adult Tobacco Survey (GATS) conducted during 2009-10 indicate that $34.6 \%$ of the adults ( $47.9 \%$ males and $20.3 \%$ females) are current tobacco users. $14 \%$ of the adult smoke (24.3\% males and $2.9 \%$ females) and similar number of students, whereas in Australia daily smoking rate for smokes is 17\% in 2007 and around $70 \%$ of laryngeal cancers are attributed fully or in part to tobacco smoking [22] [23]. In Australia, the rate of smoking is approximately $15.1 \%$, whereas in the Northern Territory is considered the highest smoking rate near $50 \%$ as compared to any state or territory in Australia [24].

Studies on bidi smoking, the most common form of tobacco smoking in India, provide a strong association of bidi smoking with risk of developing cancer is 5 9 times greater than for nonsmokers at various sites, such as oral cavity, pharynx, and larynx, which is further multiply about 17 times for heavy smokers of 80 or more per day [25]. Pednekar et al. in their Mumbai cohort found that the prevalence of oral cancers was $42 \%$ raised among bidi smokers as compared with cigarette smokers [26]. A study showed that cannabis smoke used in different Australian regions have a carcinogenic and mutagenic potential because it contains a higher level of carcinogens than cigarette smoke [27].

\subsection{Smokeless Tobacco (SLT)}

Many different forms of smokeless tobacco are used in India, which are very popular in large number of people. Among them, the use of betel quid chewing (pan) is extremely widespread in many regions of India. Along with this, gutka, khara, mawa, zarda, and khainni, are mixes by vendors and are all dry mixtures of areca nut flakes, lime, tobacco power [28]. It is also used as a moist snuff containing lime with tobacco, vegetable oil and water (Naswar/Nass), mainly according to local traditions and for the purpose of enhancing flavor and also in the form of dried tobacco powder applied on gums and teeth [29]. 
About $10 \%$ of the world's population chews betel quid regularly and most prevalent in Asia-Pacific region but use of betel quid is not quite relevant to Australia [30] [31]. Areca nut alone is a long-established carcinogen and causally connected with a premalignant condition known oral submucous fibrosis (OSMF) and oral cancer [32]. Areca nut use is very exceptional in the Western world due to its scarcity. In India alone, five million people $(0.5 \%$ of the population of India) have OSMF [33]. In Australian native citizens are changing from alcohol to cannabis utilization since the restrictions on alcohol in remote communities; thus there is an epidemic of cannabis use in remote Indigenous communities in the Northern Territory [34].

Australian immigration statistics show that $30 \%$ of new arrivals in Australia (New South Wales) are from Indian subcontinent, China, and Taiwan, are more likely to be responsible for this tradition of tobacco chewing, as they are closely connected to sociocultural and religious activities long after they migrate to Australia [35]. Univariate analysis revealed that, in terms of oral dipping products, the risk was 7.3 for consumption of gutka, 5.3 for consumption of chewing tobacco and 4 for consumption of supari (pure areca nut) and the minor risk was found for mishiri [36].

\subsection{Alcohol Consumption}

Drinking alcohol on regular basis is an important risk factor for HNC and it is associated with an increased risk, which is dose-dependent. A regular consumption of $4-5$ drinks daily, increase oral cancer risk by $2-3$ folds than non-drinkers but, in case of heavy alcohol drinking risk increase up to $7 \%$ to $19 \%$ oral cavity cancer [37]. A prospective study in India has found that alcohol consumption increases the incidence by $49 \%$ among current users and $90 \%$ in past drinkers [38]. According to Ferlay, oral cavity cancer has its highest rates of incidence in Western Europe, India, South Africa and Australia. In 2008 the Australian Department of Health reported that Australia is 30th highest alcohol-consuming country of 180 countries worldwide [39] [40].

The consumption of alcohol was very high in India; in $201611.4 \mathrm{~L}$ per capita per year with age above 15 years old and among them 30\% are regular and 11\% moderate to heavy drinker. However, the consumption is very high in the Northern Territory: approximately $15 \mathrm{~L}$ and New South Wales $13 \mathrm{~L}$ of pure alcohol per year have been consumed by adults ( $\geq 15$ years old) [41] [42].

\subsection{Alcohol in Combination with Smoking}

Taking alcohol in combination with tobacco in any form further enhances risk of oral cancer by 11 times [37]. A study conducted in northern India on oral cancer (buccal and labial mucosa) showed that alcohol alone had a nonsignificant odd ratio of 2.7, however there was a significant odd ratio seen with alcohol with bidi smoking (8.5), alcohol and pan tobacco chewing (20), and with alcohol, pan, and smoking altogether (31.4\%) [29]. 


\subsection{Human Papilloma Virus (HPV)}

The human papilloma virus (HPV) has been identified as an etiological factor in HNC mainly oropharyngeal cancer [43]. The overall prevalence of HPV is about $50 \%$ globally and their incidence increased by $25 \%$ in last 20 years and is the third predominant risk factor for HNSCC with the highest prevalence in cancer of tonsil and base of tongue [44].

HPV-16 is the most common genotype, occurring in $90 \%$ of high risk HPV oropharyngeal carcinomas [45]. In India HPV incidence ranges from $33.6 \%$ in the Eastern region to $67 \%$ in South India and $15 \%$ in Western India. A study showed a rate of HPV infections of $56.3 \%$ in cancers of the mandible, $37.5 \%$ in cheek, and $38.6 \%$ in maxilla are reported in the advanced stages (III, IV) had higher infection rates as compared to earlier stage. Lesions of the tongue had the highest rate (9 of 11) of HPV infection [46].

Within Australia, 8844 cases of HPV-related oropharyngeal cancers were diagnosed between 1982 to 2005 . This particular study reported that the incidence of HPV-related cancers significantly increased annually among both males (1.42\% per annum) and females (1.04\% per annum) P value $<0.01$ [47].

Increase in incidence found with use of newer techniques that could be helpful for $45 \%$ ( 26 of 57 ) of tumors tested were positive for P16 in patients from the Northern Territory in Australia; however, 63\% of those were Indigenous Australians [41] [48]. The prevalence of HPV-related HNC in Australia is currently increasing; this trend may be attributable to changes in sexual behaviors, particularly oral sex [47]. Synergistic association between HPV and other notable risk factors (alcohol consumption and smoking) remains controversial [49].

The vaccination of HPV has not been incorporated in the national immunization program of India. There is dispute about using the HPV vaccine in Australian men; it is currently indicated for use in young women. In Australia, the current HPV vaccination program for females aged 12 to 13 years was introduced in 2007 and may have an effect on the future incidence of these cancers [50].

\subsection{Oral Hygiene}

Poor oral hygiene also causes oral cancer. In one study, more than $85 \%$ of oral cancer patients had poor oral hygiene [7]. Poor oral hygiene related attributable risk is around $32 \%$ for men and $64 \%$ for women in India. Patients wearing poorly fitting or defective complete dentures for more than 15 years and not visiting a dentist regularly were highly associated with oral cancer but, least has occurred in Australian population who has received dental care [51] [52]. Periodontal disease has been found in connection with OSCC [53].

However, In India oral precancerous conditions are also prevalent which are helpful in diagnosing majority of oral cancer cases and exclusively present in tobacco users.

Oral lesions that have been identified clinically as having potential for malignant conversion include leukoplakia, erythroplakia, lichen planus, and submuc- 
ous fibrosis. Reported rates of malignant transformation of leukoplakia range from less than $1 \%$ to $18 \%$ [54]. Erythroplakias are the most severe and carry a much greater risk of malignancy transformation followed by leukoplakia with $0.13 \%$ to $10 \%$ whereas in Australia malignant transformation rate of leukoplakia is approximately $1 \%$ but OSMF has highest transformation about $17 \%$ considered as important factor in the raising incidences of oral cancer in people 35 years and below in India [29].

\subsection{UV Radiation}

Ultraviolet (UV) light exposure may cause HNC, particularly lip cancer, is mainly caused by UVB $(290-320 \mathrm{~nm})$ irradiation due to increased exposure of the mucosal linning of the lips to the sun and cancer in the lower lip occurs in around $90 \%$ of all cases [55] [56]. A high incidence of lip cancer has been reported among whites and is about 3 times higher in men than in the women, which may be due to more outdoor occupations, smoking, and sun exposure among men. The variations in the incidence of lip cancer in the Australian states are probably attributable to differences in the rural and urban populations with respect to exposure to UV as a risk factor [55] [57].

In Australia, more than $50 \%$ of $\mathrm{HNC}$ in white people are located on the lip. [58]. However, HNC of the lip is not very common in nonwhite populations, in particular Indigenous Australians [59]. The reported incidence of skin cancer of HNC in India is less than 1\% of all the cancers. BCC is the commonest skin cancer worldwide, but in India SCC as the most prevalent skin malignancy [60]. The incidence shows an inverse relation with the degree of pigmentation, presumably due to protective effect of eumelanin on ultraviolet light (UV)-induced damage [61].

In Western Australia annual incidence of lip cancer was 8.9 in 100,000 and 2.7 in 100,000 for males and females, respectively, from 1982 to 2006 [62].

\subsection{Nutrition and Socioeconomic Status}

Different studies in last few years showed diet has come into view as a risk factor of HNC along with tobacco smoking, alcohol intake and HPV [50]. A study in India showed that regular consumption of fruits and green leafy vegetables reduces risk by 2 folds as compare to butter and pulses for HNC [63]. Taking daily diet rich carbohydrates, vegetable oil, fish, fruits, vegetables and lean meat decrease risk of oral cancer by $50 \%$, on the other side, too much meat consumption was considered to be a risk factor for many HNC [64].

According to the UN report published in 2017, India is home to 190.7 million underfed people, $51 \%$ women are anemic and more than $50 \%$ of elderly people of India are suffering from malnutrition but there is hardly any published quantitative data on the nutritional status of Indigenous Australians. Prevalence of malnutrition in Australia was reported at $2.5 \%$ in 2015, on average, daily smoking rate 3 times more in the lower socioeconomic group then higher [65] [66]. 
India is classified as a lower-middle-income group country by the World Bank. $90 \%$ of the oral cancer patients in rural areas belong to the lower or lower-middle socio-economic class, and $3.6 \%$ are below the poverty line based on Pareek's classification [67]. Around $80 \%$ of patients with cancers present with advance-stage incurable disease and hence increased mortality. Big reason for delayed diagnosis is the lack of easy access to healthcare, respectively further reasons included poor socio-economic status of the patient, cost of care, and high rate of illiteracy [68].

Brookes reported a significant difference between the survival of undernourished HNC patients (7.5\% at 2 years) and the survival of adequately nourished patients (57.5\% at 2 years) undergoing radiotherapy [69].

\subsection{Family History and Genetic Susceptibility}

Genetic susceptibility might play a role in the progression of cancer, but those that have revealed a high risk for HNC with respect to family history of cancer. A first-degree relative is a family member who shares about 50 per cent of their genes with a particular individual in a family beside this a higher risk of oral cavity cancer in males with a family history of smoking-related cancers than in females [70].

The prevalence of the p53 mutation is $81 \%$ in the Western world but rare in India. Multiple genetic abnormalities are common in head and cancers in India and Southeast Asia. These include a prevalence of Ha-ras mutations (35\%), loss of heterozygosity of Ha-ras (30\%), N-ras amplification (28\%), and N-myc amplification (29\%) [71].

\section{Other Risk Factors}

Environmental and occupational factors including asbestos, wood dust and leather dust can also contribute to some HNC, including in the larynx and pharynx [72].

In India large number of population dealing with Plummer-Vinson syndrome is associated with a high risk for development of carcinoma of oral cavity, oropharynx and esophagus [23].

Immunosuppressive conditions increase risk of developing oral cancers in a number of patient undergone kidney transplantation, lip cancer in patients suffering from AIDS oral carcinoma has been reported [73].

Australian diabetic patients consistently seemed to be more likely to have distant metastases of cancer at the time of diagnosis and it is involved as a risk factor not only for the development of HNC but also for oral premalignant lesions such as leukoplakia [74].

\section{Conclusions}

This review gives an idea that major risk factors are lifestyle, behavioral and environmental associated in developing various HNC in population of India and Australia. 
In India, the illiteracy, lack of infrastructure and health care facilities, are major problems. Lack of awareness is more common in the lower socio-economic class about the side effects of tobacco, and prevalent cultural beliefs lead to delay in seeking treatment and result in advanced-stage presentation of disease. People in Australia more aware about symptoms and government provide better cancer treatment facilities and early diagnosis and treatment.

The knowledge about risk factors for HNC in public health education for general population supports health promotion and tobacco prevention programs by the government, as HNC are potentially preventable.

\section{Conflicts of Interest}

The authors declare no conflicts of interest regarding the publication of this paper.

\section{References}

[1] Grégoire, V., Lefebvre, J.L., Licitra, L., Felip, E. and EHNS-ESMO-ESTRO Guidelines Working Group (2010) Squamous Cell Carcinoma of the Head and Neck: EHNS-ESMO-ESTRO Clinical Practice Guidelines for Diagnosis, Treatment and Follow-Up. Annals of Oncology, 21, 184-186. https://doi.org/10.1093/annonc/mdq185

[2] Ferlay, J., Shin, H.R., Bray, F., Forman, D., Mathers, C. and Parkin, D.M. (2010) Estimates of Worldwide Burden of Cancer in 2008: GLOBOCAN 2008. International Journal of Cancer, 127, 2893-2917. https://doi.org/10.1002/ijc.25516

[3] NICPR (2017) National Institute of Cancer Prevention and Research Program.

[4] Saranath, D. and Khanna, A. (2014) Current Status of Cancer Burden: Global and Indian Scenario. Biomedical Research, 1, 1-5.

[5] Kulkarani, M.R. (2013) Head and Neck Cancer Burden in India. International Journal of Head and Neck Surgery, 4, 29-35. https://doi.org/10.5005/jp-journals-10001-1132

[6] Australian Institute of Health and Welfare (2008) Cancer in Australia: An Overview, 2008. Australasian Association of Cancer Registries, Canberra.

[7] Sankaranarayanan, R., Ramadas, K., Thomas, G., et al. (2005) Effect of Screening on Oral Cancer Mortality in Kerala, India: A Cluster Randomised Controlled Trial. The Lancet, 365, 1927-1933. https://doi.org/10.1016/S0140-6736(05)66658-5

[8] International Agency for Research on Cancer (2010) GLOBOCAN 2008. http://globocan.iarc.fr/Pages/fact_sheets_population.aspx

[9] Argiris, A. and Eng, C. (2004) Epidemiology, Staging, and Screening of Head and Neck Cancer. Head Neck Cancer, 114, 15-60. https://doi.org/10.1007/0-306-48060-3_2

[10] Sharma, M., Madan, M., Manjari, M., Bhasin, T.S., Jain, S. and Garg, S. (2015) Prevalence of Head and Neck Squamous Cell Carcinoma (HNSCC) in Our Population: The Clinicpathological and Morphological Description of 198 Cases. http://scholar.google.com/scholar_lookup?hl=en\&publication_year=2015\&pages=827 -833\&author $=\mathrm{M}+$ Sharma\&author $=\mathrm{M}+$ Madan\&author $=\mathrm{M}+$ Manjari\&author $=\mathrm{TS}+\mathrm{Bha}$ sin\&author=S+Jain\&author $=$ S.+Garg\&title $=$ Prevalence + of + head + and + neck + squamo us+cell+carcinoma+\%28HNSCC\%29+in+our+population\%3A+the+clinico-pathologi cal+and+morphological+description+of $+198+$ cases\& 
[11] Graham, S. (1977) Dentition, Diet, Tobacco and Alcohol in the Epidemiology of Oral Cancer. Journal of the National Cancer Institute, 59, 1611-1618. https://doi.org/10.1093/jnci/59.6.1611

[12] Dayal, P.K., Mani, N.J. and Bhargava, K. (1978) Prevalence of Oral Cancer and Precancerous Lesions in 'Pan'/'Supari' Chewers. Indian Journal of Public Health, 22, 234-245.

[13] Mehta, F.S. and Hamner, J.E. (1993) Tobacco Habits in India. In: Tobacco-Related Oral Mucosal Lesions and Conditions in India, Jaypee Brothers, New Delhi, 89-99.

[14] Mishra, A., Sinhg, V.P. and Verma, V. (2009) Environmental Effect on Head and Neck Cancers in India. Journal of Clinical Oncology, 27, 7059.

[15] Zhang, X., Condon, J.R., Rumbold, A.R., Cunningham, J. and Roder, D.M. (2011) Estimating Cancer Incidence in Indigenous Australians. Australian and New Zealand Journal of Public Health, 35, 477-485. https://doi.org/10.1111/j.1753-6405.2011.00762.x

[16] Ragin, C., Modugno, F. and Gollin, S. (2007) The Epidemiology and Risk Factors of Head and Neck Cancer: A Focus on Human Papillomavirus. Journal of Dental Research, 86, 104-114. https://doi.org/10.1177/154405910708600202

[17] Agarwal, A.K., Sethi, A., Sareen, D. and Dhingra, S. (2011) Treatment Delay in Oral and Oropharyngeal Cancer in Our Population: The Role of Socio-Economic Factors and Health-Seeking Behaviour. Indian Journal of Otolaryngology and Head \& Neck Surgery, 63, 145-150. https://doi.org/10.1007/s12070-011-0134-9

[18] Argiris, A., Karamouzis, M.V., Raben, D. and Ferris, R.L. (2008) Head and Neck Cancer. The Lancet, 371, 1695-1709. https://doi.org/10.1016/S0140-6736(08)60728-X

[19] WHO (2011) WHO Report on the Global Tobacco Epidemic. The MPOWER Package, Warning about the Dangers of Tobacco. WHO, Geneva.

[20] Jha, P., Jacob, B., Gajalakshmi, V., Gupta, P.C., Dhingra, N., Kumar, R., et al. (2008) A Nationally Representative Case-Control Study of Smoking and Death in India. The New England Journal of Medicine, 358, 1137-1147. https://doi.org/10.1056/NEJMsa0707719

[21] Jandoo, T. and Mehrotra, R. (2008) Tobacco Control in India: Present Scenario and Challenges Ahead. Asian Pacific Journal of Cancer Prevention, 9, 805-810.

[22] Australian Institute of Health and Welfare (2008) Australia's Health. Australian Institute of Health and Welfare, Canberra.

[23] Ram, F., Lahiri, S., Parasuraman, S., LaduSingh, L., Paswan, B., Singh, S.K. and Das, K.C. (2010) Global Adult Tobacco Survey (GATS) India, 2009-2010. International Institute for Population Sciences (IIPS), Mumbai and Ministry of Health and Family Welfare, Government of India, New Delhi.

[24] Australian Institute of Health and Welfare (2010) National Drug Strategy Household Survey Report. Drug Statistics Series No. 25, Cat No. PHE145. Australian Institute of Health and Welfare, Canberra.

[25] Neville, B.W. and Day, T.A. (2002) Oral Cancer and Precancerous Lesions. CA: $A$ Cancer Journal for Clinicians, 52, 195-215. https://doi.org/10.3322/canjclin.52.4.195

[26] Pednekar, M.S., Gupta, P.C., Yeole, B.B. and Hébert, J.R. (2011) Association of Tobacco Habits, Including BIDI Smoking, with Overall and Site Specific Cancer Incidence: Results from the Mumbai Cohort Study. Cancer Causes Control, 22, 859-868. https://doi.org/10.1007/s10552-011-9756-1

[27] Wu, T.C., Tashkin, D.P., Djahed, B. and Rose, J.E. (1988) Pulmonary Hazards of 
Smoking Marijuana as Compared with Tobacco. The New England Journal of Medicine, 318, 347-351. https://doi.org/10.1056/NEJM198802113180603

[28] Kekatpure, V. and Kurlakose, M.A. (2010) Oral Cancer in India: Learning from Different Population. National Newsletter and Website from New York Presbyterian Hospital, 14.

http://www.nypcancerprevention.com/issue/14/cancer_prevention/feature.India.sht $\underline{\mathrm{ml}}$

[29] Chaturvedi, P. (2009) Head and Neck Surgery. Journal of Cancer Research and Therapeutics, 5, 143.

[30] Gupta, P.C. and Ray, C.S. (2004) Epidemiology of Betel Quid Usage. Annals of the Academy of Medicine, Singapore, 33, 31-36.

[31] Proia, N., Paszkiewicz, G., Nasca, M., Franke, G. and Pauly, J. (2006) Smoking and Smokeless Tobacco-Associated Human Buccal Cell Mutations and Their Association with Oral Cancer-A Review. Cancer Epidemiology, Biomarkers \& Prevention, 15, 1061-1077. https://doi.org/10.1158/1055-9965.EPI-05-0983

[32] Gupta, P.C., Sinor, P.N., Bhonsle, R.B., Pawar, V.S. and Mehta, H.C. (1998) Oral Sub-Mucous Fibrosis in India: A New Epidemic? The National Medical Journal of India, 11, 113-116. https://doi.org/10.1111/j.1600-0714.2005.00325.x

[33] Rajalalitha, P. and Vali, S. (2005) Molecular Pathogenesis of Oral Submucous Fibrosis-A Collagen Metabolic Disorder. Journal of Oral Pathology \& Medicine, 34, 321-328.

[34] Lee, K.S., Conigrave, K.M., Patton, G.C. and Clough, A.R. (2009) Cannabis Use in Remote Indigenous Communities in Australia: Endemic Yet Neglected. The Medical Journal of Australia, 190, 228-229.

[35] Sukumar, S., Coleman, H.G. and Cox, S.C. (2012) Areca Nut Chewing in an Expatriate Population in Sydney: Report of Two Cases. Australian Dental Journal, 57, 373-378. https://doi.org/10.1111/j.1834-7819.2012.01716.x

[36] Mallath, M.K., Taylor, D.G., Badwe, R.A., Rath, G.K., Shanta, V., Pramesh, C.S., Digumarti, R., Sebastian, P., Borthakur, B.B., Kalwar, A., Kapoor, S., Kumar, S., Gill, J.L., Kuriakose, M.A., Malhotra, H., Sharma, S.C., Shukla, S., Viswanath, L., Chacko, R.T., Pautu, J.L., Reddy, K.S., Sharma, K.S., Purushotham, A.D. and Sullivan, R. (2014) The Growing Burden of Cancer in India: Epidemiology and Social Context. The Lancet Oncology, 15, e205-e212.

[37] Subapriya, R., Thangavelu, A., Mathavan, B., et al. (2007) Assessment of Risk Factors for Oral Squamous Cell Carcinoma in Chidambaram, Southern India: A Case-Control Study. European Journal of Cancer Prevention, 16, 251-256. https://doi.org/10.1097/01.cej.0000228402.53106.9e

[38] Cancela, M.C., Ramadas, K., Fayette, J.-M., et al. (2009) Alcohol Intake, Oral Cavity Cancer Risk among Men in a Prospective Study in Kerala, India. Community Dentistry and Oral Epidemiology, 37, 342-349. https://doi.org/10.1111/j.1600-0528.2009.00475.x

[39] Globocan, F.J. (2002) Cancer Incidence, Mortality and Prevalence Worldwide. IARC Press, Lyon.

[40] Australian Bureau of Statistics (2010) Apparent Consumption of Alcohol, Australia, 2008-09. Australian Bureau of Statistics, Canberra.

[41] Jayaraj, R., Thomas, M., Thomson, V., Griffin, C., Mayo, L., Whitty, M., d'Abbs, P. and Nagel, T. (2012) High Risk Alcohol-Related Trauma among the Aboriginal and Torres Strait Islanders in the Northern Territory. Substance Abuse Treatment, Pre- 
vention, and Policy, 7, 33. https://doi.org/10.1186/1747-597X-7-33

[42] Chikritzhs, T., Stockwell, T. and Pascal, R. (2005) The Impact of the Northern Territory's Living with Alcohol Program, 1992-2002: Revisiting the Evaluation. Addiction, 100, 1625-1636. https://doi.org/10.1111/j.1360-0443.2005.01234.x

[43] Gillison, M.L., et al. (2000) Evidence for a Causal Association between Human Papillomavirus and a Subset of Head and Neck Cancers. Journal of the National Cancer Institute, 92, 709-720. https://doi.org/10.1093/jnci/92.9.709

[44] Gillison, M.L. (2004) Human Papillomavirus-Associated Head and Neck Cancer Is a Distinct Epidemiologic, Clinical, and Molecular Entity. Seminars in Oncology, 31, 744-754. https://doi.org/10.1053/j.seminoncol.2004.09.011

[45] Muñoz, N., Bosch, F. and de Sanjosé, S. (2003) Epidemiologic Classification of Human Papillomavirus Types Associated with Cervical Cancer. The New England Journal of Medicine, 348, 518-527. https://doi.org/10.1056/NEJMoa021641

[46] Nagpal, J.K., Patnaik, S. and Das, B.R. (2002) Prevalence of High-Risk Human Papilloma Virus Types and Its Association with p53 Codon 72 Polymorphism in Tobacco Addicted Oral Squamous Cell Carcinoma (OSCC) Patients of Eastern India. International Journal of Cancer, 97, 649-653. https://doi.org/10.1002/ijc.10112

[47] Hocking, J.S., Stein, A., Conway, E.L., Regan, D., Grulich, A., Law, M. and Brotherton, J.M. (2011) Head and Neck Cancer in Australia between 1982 and 2005 Show Increasing Incidence of Potentially HPV-Associated Oropharyngeal Cancers. British Journal of Cancer, 104, 886-891. https://doi.org/10.1038/sj.bjc.6606091

[48] Intrapanya, M., Jayaraj, R., Scott, C., Baxi, S., Curtin, J., Lys, I., Mileva, M. and Thomas, M.E. (2012) Human Papilloma Virus in Oropharyngeal Cancers. ANZ Journal of Surgery, 82, 189-190. https://doi.org/10.1111/j.1445-2197.2011.05977.x

[49] Smith, E., Rubenstein, L. and Haugen, T. (2010) Tobacco and Alcohol Use Increases the Risk of both HPV-Associated and HPV Independent Head and Neck Cancers. Cancer Causes Control, 21, 1369-1378. https://doi.org/10.1007/s10552-010-9564-Z

[50] Shefer, A., Markowitz, L., Deeks, S., Tam, T., Irwin, K., Garland, S.M. and Schuchat, A. (2008) Early Experience with Human Papillomavirus Vaccine Introduction in the United States, Canada and Australia. Vaccine, 26, K68-K75. https://doi.org/10.1016/j.vaccine.2008.05.065

[51] Guneri, P., Cankaya, H., Yavuzer, A., et al. (2005) Primary Oral Cancer in a Turkish Population Sample: Association with Sociodemographic Features, Smoking, Alcohol, Diet, Dentition. Oral Oncology, 41, 1005-1012. https://doi.org/10.1016/j.oraloncology.2005.06.002

[52] Holmes, L.J., Desvignes-Kendrick, M. and Slomka, J. (2008) Is Dental Care Utilization Associated with Oral Cavity Cancer in a Large Sample of Community-Based United States Residents? Community Dentistry and Oral Epidemiology, 37, 134-142. https://doi.org/10.1111/j.1600-0528.2008.00450.x

[53] Meyer, M., Joshipura, K. and Giovannucci, E. (2008) A Review of the Relationship between Tooth Loss, Periodontal Disease, and Cancer. Cancer Causes Control, 19, 895-907. https://doi.org/10.1007/s10552-008-9163-4

[54] Silverman, S., Gorsky, M. and Lozada, F. (1984) Oral Leukoplakia and Malignant Transformation: A Follow-Up Study of 257 Patients. Cancer, 53, 563-568. https://doi.org/10.1002/1097-0142(19840201)53:3<563::AID-CNCR2820530332>3.0 .CO;2-F

[55] Perea-Milla López, E., Miñarro-Del Moral, R.M., Martínez-García, C., Zanetti, R., Rosso, S., Serrano, S., Aneiros, J.F., Jimenez-Puente, A. and Redondo, M. (2003) 
Lifestyles, Environmental and Phenotypic Factors Associated with Lip Cancer: A Case-Control Study in Southern Spain. British Journal of Cancer, 88, 1702-1707. https://doi.org/10.1038/sj.bjc.6600975

[56] Vukadinovic, M., Jezdic, Z., Petrovic, M., Medenica, L.M. and Lens, M. (2007) Surgical Management of Squamous Cell Carcinoma of the Lip: Analysis of a 10-Year Experience in 223 Patients. Journal of Oral and Maxillofacial Surgery, 65, 675-679. https://doi.org/10.1016/j.joms.2006.03.054

[57] Ariyawardana, A. and Johnson, N.W. (2013) Trends of Lip, Oral Cavity and Oropharyngeal Cancers in Australia 1982-2008: Overall Good News But with Rising Rates in the Oropharynx. BMC Cancer, 13, 333. https://doi.org/10.1186/1471-2407-13-333

[58] Sugerman, P. and Savage, N. (2002) Oral Cancer in Australia: 1983-1996. Australian Dental Journal, 47, 45-56. https://doi.org/10.1111/j.1834-7819.2002.tb00303.x

[59] Warnakulasuriya, S. (2009) Global Epidemiology of Oral and Oropharyngeal Cancer. Oral Oncology, 45, 309-316. https://doi.org/10.1016/j.oraloncology.2008.06.002

[60] Godbole, V.K., Toprani, H.T. and Shah, H.H. (1968) Skin Cancer in Saurashtra. Indian Journal of Pathology \& Bacteriology, 11, 183-189.

[61] Yamaguchi, Y., Beer, J.Z. and Hearing, V.J. (2008) Melanin Mediated Apoptosis of Epidermal Cells Damaged by Ultraviolet Radiation: Factors Influencing the Incidence of Skin Cancer. Archives of Dermatological Research, 300, S43-S50. https://doi.org/10.1007/s00403-007-0807-0

[62] Abreu, L., Kruger, E. and Tennant, M. (2009) Lip Cancer in Western Australia, 1982-2006: A 25-Year Retrospective Epidemiological Study. Australian Dental Journal, 54, 130-135.

[63] Sinha, R., Anderson, D.E., McDonald, S.S. and Greenwald, P. (2003) Cancer Risk and Diet in India. Journal of Postgraduate Medicine, 49, 222-228.

[64] Freedman, N.D., Park, Y., Subar, A.F., Hollenbeck, A.R., Leitzmann, M.F., Schatzkin, A. and Abnet, C.C. (2008) Fruit and Vegetable Intake and Head and Neck Cancer Risk in a Large United States Prospective Cohort Study. International Journal of Cancer, 122, 2330-2336. https://doi.org/10.1002/ijc.23319

[65] Semwal, J., Vyas, S., Juyal, R. and Sati, H.C. (2014) Nutritional Status and Associated Comorbidities among the Elderly in Doiwala Block, Dehradun. Indian Journal of Community Health, 26, 197-203.

[66] Saethre, E. (2005) Nutrition, Economics and Food Distribution in an Australian Aboriginal Community. Anthropological Forum, 15, 151-169. https://doi.org/10.1080/00664670500135212

[67] Pareek, U. and Trivedi, G. (1995) Manual of Socio-Economic Status Scale (Rural). Manasayan Publishers, New Delhi.

[68] Pai, S.A. (2002) Gutkha Banned in Indian States. The Lancet Oncology, 3, 521. https://doi.org/10.1016/S1470-2045(02)00862-8

[69] Brookes, G.B. (1985) Nutritional Status-A Prognostic Indicator in Head and Neck Cancer. Otolaryngology_Head and Neck Surgery, 93, 69-74. https://doi.org/10.1177/019459988509300114

[70] Negri, E., Boffetta, P., Berthiller, J., Castellsague, X., Curado, M.P., Dal Maso, L., et al. (2009) Family History of Cancer: Pooled Analysis in the International Head and Neck Cancer Epidemiology Consortium. International Journal of Cancer, 124, 394-401. https://doi.org/10.1002/ijc.23848

[71] Paterson, I.C., Eveson, J.W. and Prime, S.S. (1996) Molecular Changes in Oral Can- 
cer May Reflect Aetiology and Ethnic Origin. European Journal of Cancer Part B: Oral Oncology, 32, 150-153. https://doi.org/10.1016/0964-1955(95)00065-8

[72] Langevin, S.M., McClean, M.D., Michaud, D.S., Eliot, M., Nelson, H.H. and Kelsey, K.T. (2013) Occupational Dust Exposure and Head and Neck Squamous Cell Carcinoma Risk in a Population-Based Case-Control Study Conducted in the Greater Boston Area. Cancer Medicine, 2, 978-986. https://doi.org/10.1002/cam4.155

[73] Berrino, F., Sant, M., Verdecchia, V., Capocaccia, R., Hakulinen, T. and Esteve, J. (1995) Survival of Cancer Patients in Europe. The Eurocare Study. IARC Scientific Publication, 132.

[74] Albrecht, M., Bánóczy, J., Dinya, E. and Tamás, G. (1992) Occurrence of Oral Leukoplakia and Lichen Planus in Diabetes Mellitus. Journal of Oral Pathology \& Medicine, 21, 364-366. https://doi.org/10.1111/j.1600-0714.1992.tb01366.x 